\title{
First measurements of radar coherent scatter by the Radio Aurora Explorer CubeSat
}

\author{
H. Bahcivan, ${ }^{1}$ J. W. Cutler, ${ }^{2}$ M. Bennett, ${ }^{3}$ B. Kempke, ${ }^{2}$ J. C. Springmann, ${ }^{2}$ J. Buonocore, ${ }^{1}$ \\ M. Nicolls, ${ }^{1}$ and R. Doe ${ }^{1}$ \\ Received 3 May 2012; revised 11 June 2012; accepted 11 June 2012; published 18 July 2012.
}

[1] The Radio Aurora Explorer CubeSat detected the first radar echoes during the solar storm of March 8, 2012. The $300 \mathrm{~s}$ ground-to-space bi-static radar experiment was conducted in conjunction with the Poker Flat Incoherent Scatter Radar in the local morning ( $~ 8$ am) over Poker Flat, Alaska. The geomagnetic conditions for the $E$ region field-aligned irregularity generation were optimal due to strong (about $1500 \mathrm{~m} / \mathrm{s}) F$ region ion drifts and sufficient $E$ region ionization (electron densities were $\sim 2 \times 10^{11} \mathrm{~m}^{-3}$ ). The corresponding $E$ region electric field of $\sim 80 \mathrm{mV} / \mathrm{m}$ was larger than the excitation threshold for the Farley-Buneman instability. An auto-correlation analysis resolved, for the first time, the distribution of auroral $E$ region backscatter with $3 \mathrm{~km}$ resolution in altitude and sub-degree resolution in aspect angle. Moreover, the measured Doppler velocities of the UHF scatter shows the phase speed saturation of the meter-scale plasma waves. The measured Doppler velocity is in excellent agreement with the $C_{s} \cos \theta$ formula for auroral $E$ region irregularities. Citation: Bahcivan, H., J. W. Cutler, M. Bennett, B. Kempke, J. C. Springmann, J. Buonocore, M. Nicolls, and R. Doe (2012), First measurements of radar coherent scatter by the Radio Aurora Explorer CubeSat, Geophys. Res. Lett., 39, L14101, doi:10.1029/2012GL052249.

\section{Introduction}

[2] Radio Aurora Explorer (RAX) is a CubeSat-based ground-to-space bi-static radar experiment designed to investigate the causes of upper atmospheric/ionospheric turbulence driven by solar wind and magnetospheric electromagnetic forcing. The plasma turbulence in the ionospheric $E$ and $F$ regions is composed of field-aligned irregularities (FAI) of electron density driven by various plasma instabilities.

[3] Previously, FAI measurements have been obtained using ground-based coherent scatter radars, however, due to near-vertical magnetic field line geometry in the highlatitudes, it has been difficult to achieve scatter perpendicularity. In particular, the ground-based coherent scatter radar measurements made at very low elevations could not resolve

\footnotetext{
${ }^{1}$ Center for Geospace Studies, SRI International, Menlo Park, California, USA

${ }^{2}$ Department of Aerospace Engineering, University of Michigan, Ann Arbor, Michigan, USA.

${ }^{3}$ Jet Propulsion Laboratory, NASA, Pasadena, California, USA.

Corresponding author: H. Bahcivan, Center for Geospace Studies, SRI International, 333 Ravenswood Ave., G284, Menlo Park, CA 94025, USA. (hasan.bahcivan@sri.com)

(C)2012. American Geophysical Union. All Rights Reserved. 0094-8276/12/2012GL052249
}

the FAI in high spatial resolution and HF radars were subject to refraction resulting in source location ambiguity.

[4] The unique radar scattering geometry of a RAX experiment composed of a transmitter on the ground and an orbiting receiver in space enables unique high-resolution measurements of FAI. The RAX mission science and radar system was described in detail in Bahcivan et al. [2009] and Bahcivan and Cutler [2012]. Moreover, the RAX mission affords the opportunity to measure vector electric fields and plasma densities probed simultaneously by the incoherent scatter radar, enabling to establish a direct relationship between the FAI and the ionospheric drivers.

[5] The RAX-2 satellite (shown in Figure 1) was launched on October 28, 2011 from Vandenberg Air Force Base to a $104^{\circ}$ inclination, elliptical orbit $(400-820 \mathrm{~km})$. The launch was provided by NASA's Educational Launch of Nanosatellites (ELaNa) program. Following a successful spacecraft checkout, RAX II conducted the first experiment with the Poker Flat Incoherent Scatter Radar (PFISR) on November 22,2011 . Due to the snapshot nature of each experiment lasting only $300 \mathrm{~s}$ and the probability of geophysical activity at a given time being low, a large number of experiments are needed to detect backscatter from FAI. For this reason, the mission lifetime was set at 1 year, assuming 1-2 experiment per week. As of May 1, 2012, 19 experiments have been conducted. The results from the most recent two experiments clearly show $E$ region radar backscatter. This letter presents the observations from the 18th experiment.

\section{Experiment Description}

[6] The satellite altitude of $800 \mathrm{~km}$ (the satellite was actually at the altitude of $811 \mathrm{~km}$ ) and the satellite track shown by the dashed black line. The RAX radar receiver was turned on for $300 \mathrm{~s}$ over the experimental zone, starting at 17:10:24 UT on March 8, 2012, collecting 14-bit I and Q samples at a rate of 1 MSPS each. The satellite track shown in this figure covers a duration of $170 \mathrm{~s}$, beginning at $75 \mathrm{~s}$ and ending at $245 \mathrm{~s}$ into the experiment.

[7] The blue cross in Figure 2 shows the location of PFISR on the ground. PFISR transmitted pulses in six beam directions. The beam dedicated to RAX reception was pointed at $20.8^{\circ}$ east of north and at $58^{\circ}$ elevation, sending $100 \mu \mathrm{s}$ uncoded pulses at $449 \mathrm{MHz}$ every $10 \mathrm{~ms}$. Halfway between the $100 \mu$ s pulses, $480 \mu$ s long pulses were transmitted to diagnose the background ionosphere using the incoherently scattered signals received back at PFISR. These pulses were transmitted at $449.5 \mathrm{MHz}$ alternating between the 6 directions, one of which coinciding with the direction of the $100 \mu$ s pulse. 


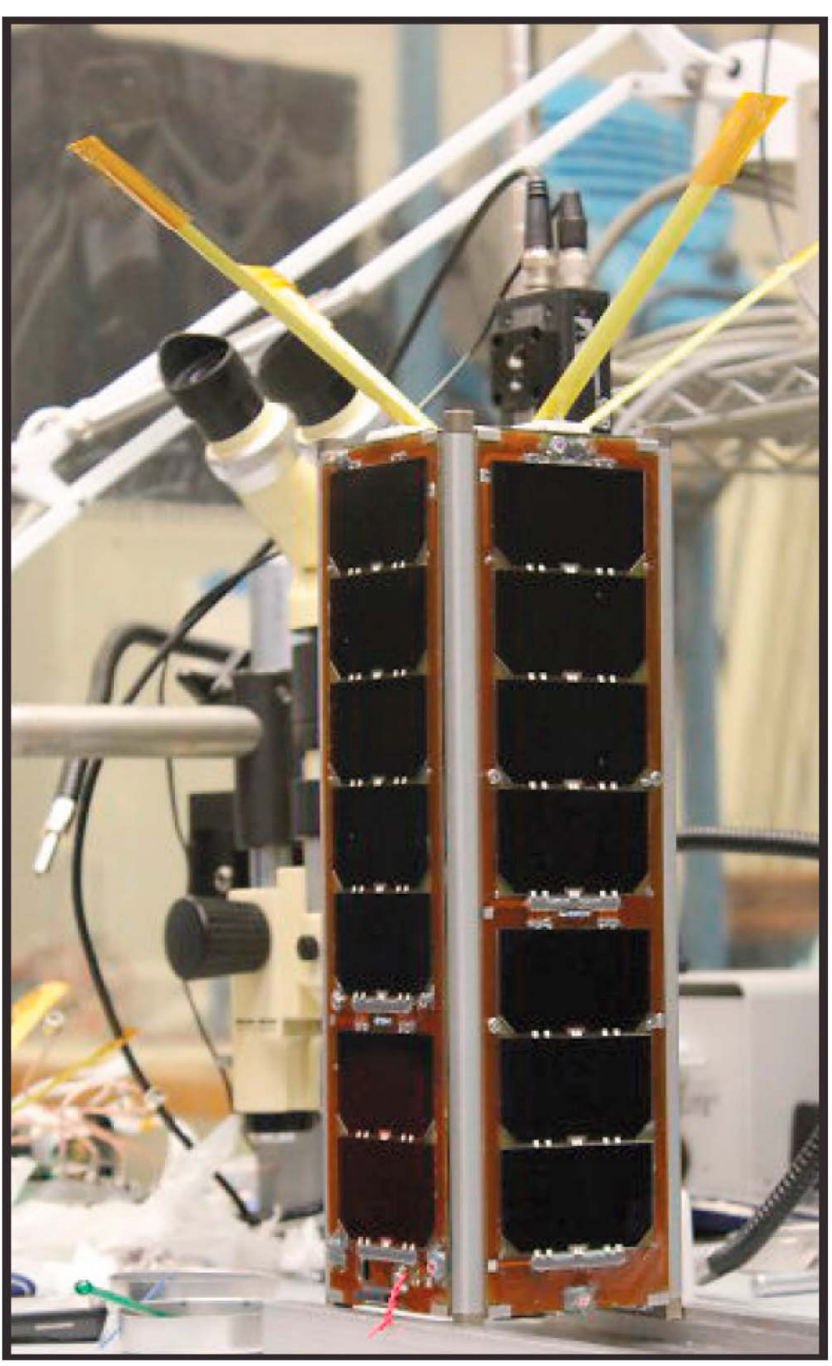

Figure 1. The RAX-2 spacecraft.

[8] Every 10 of the RAX I and Q sample stream (collected at $1 \mathrm{MHz}$ ) were coherently averaged together resulting in a record length of 1000 samples per inter-pulse-period of $10 \mathrm{~ms}$. Then, the signal power was computed and 100 records were incoherently averaged to form a range-time-intensity profile at $1 \mathrm{~s}$ resolution, as shown in Figure 3 . Note that due to the variable amount of interference, no attempt was made to determine the noise floor. Instead, a preset noise power (computed based on lab measurements) was programmed into the on-board software. This noise floor was used to convert signal power to signal-to-noise ratio. After on-board computing that lasts $\sim 1 \mathrm{~h}$, the $1.2 \mathrm{~GB}$ of raw I and Q data are finally converted to a post-compression $50 \mathrm{~KB}$ Range-Timeintensity (RTI) image and downloaded to a ground station.

[9] In the several weeks following this experiment, the raw I and Q data corresponding to the 235th second (at the original $1 \mathrm{MHz}$ rate) was also downloaded for Doppler analysis. The interference was carefully removed by matching a model signal to the interfering signal, which looked like Gaussian spikes lasting 7-8 $\mu \mathrm{s}$ and repeating at $10 \mathrm{KHz}$. These spikes were first removed and the missing data were interpolated using the adjacent samples. Note that the echo lasts about $140 \mu \mathrm{s}$ and appeared to have a correlation time in excess of

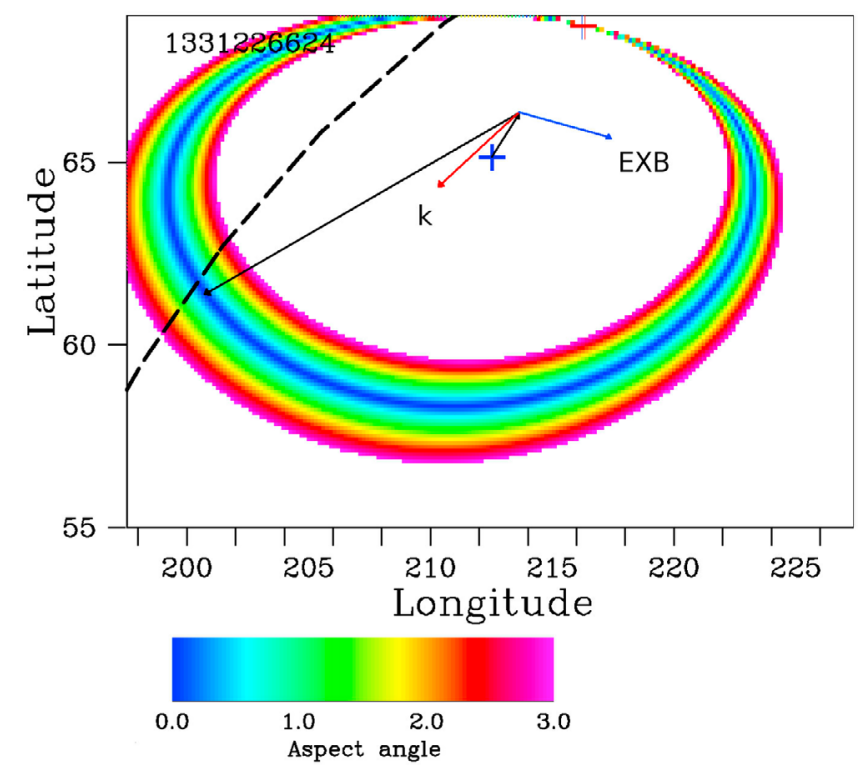

Figure 2. Experimental geometry showing the loci of perpendicularity at the spacecraft altitude (colored rings), spacecraft trajectory (dashed line), the incoming and scattered radar wave direction (thin black line), and the scattering Bragg wavevector (red vector). Blue cross marks the location of PFISR on the ground. Finally, the blue vector shows the direction of the $\mathbf{E} \times \mathbf{B}$ drift during the pass.

$100 \mu \mathrm{s}$, therefore, the effect of the interpolation in the analysis here is insignificant.

[10] To measure the Doppler velocity of FAI, we computed the autocorrelation function (ACF) lag at $90 \mu$ s delay. This ACF was computed from 98 I and Q records corresponding to the 235th second (2 were manually excluded). We first computed the Doppler shift of the direct pulse from PFISR to RAX. Then, we applied a small frequency offset $\Delta f$ (for

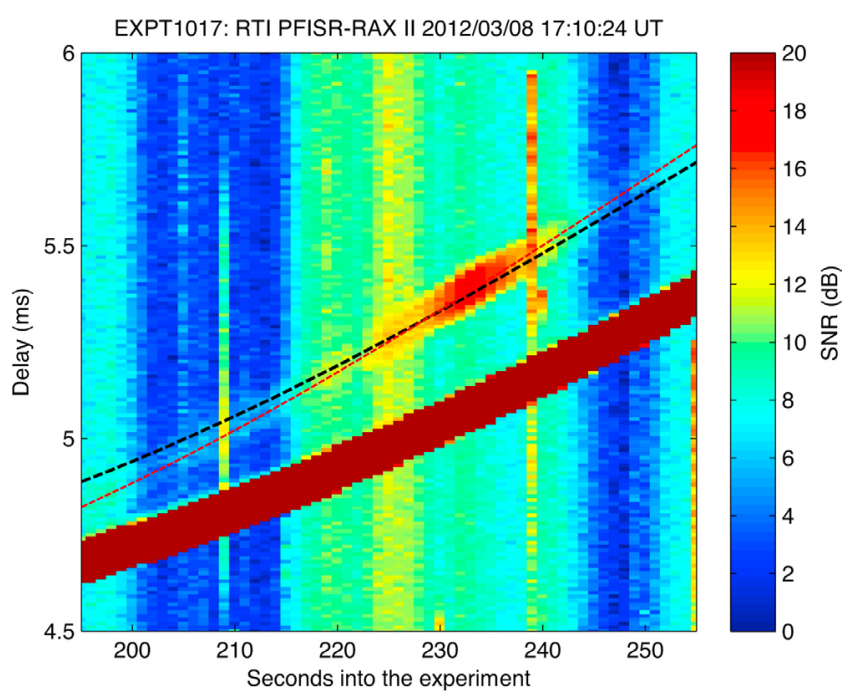

Figure 3. Range-time-intensity plot for the duration of $E$ region echoes observed by RAX. The black line marks the arrival time of echoes from the altitude of $100 \mathrm{~km}$. The red line is a visual fit to the trace of the echo peak. 


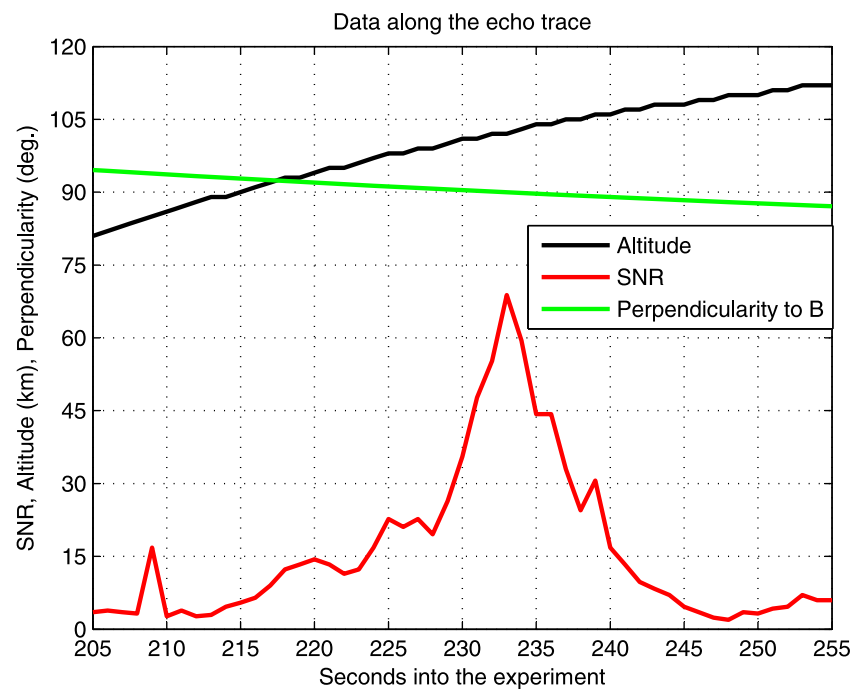

Figure 4. SNR (red line), aspect angle (green line), and altitude (black line) along the red trace shown in Figure 3.

compensating the TX-RX mismatch) to match the computed Doppler shift to the Doppler shift corresponding to the projection velocity of the spacecraft along the PFISR line-ofsight, which was obtained from the ephemeris provided by the Joint Space Operations Center (JspOC). We then applied the same $\Delta f$ to the Doppler shift of the I and Q samples containing the echo. Finally, we obtained the Doppler velocity of FAI by multiplying the corrected Doppler shift with the radar Bragg wavelength for the scattering geometry of the 235 th second.

\section{Observations}

[11] Figure 3 shows the RTI plot for this experiment. RAX crossed loci-of-perpendicularity for altitudes 300 ( $F$ region), 200 , and $100 \mathrm{~km}$ ( $E$ region) at times approximately 175,205 and 235 seconds into the experiment. Echoing occurred between the times 200-250 s into the experiment. The echoes arrived $\sim 330 \mu$ s after the arrival of the direct pulse, corresponding to $E$ region scattering altitudes. The strongest echoes occurred around $235 \mathrm{~s}$, corresponding to the altitude of $102 \mathrm{~km}$. The peak SNR was $19 \mathrm{~dB}$.

[12] The black dashed-line in Figure 3 shows the expected location of the echoes originating from the altitude of $100 \mathrm{~km}$. We notice that echoes arrive somewhat earlier on the left side of the plot and somewhat later on the right side. This is because altitudes lower (higher) than $100 \mathrm{~km}$ are contributing on the left (right) side.

[13] The echo in Figure 3 was so well formed that we decided to fit a hyperbolic trace to it and determine the scattering geometry along the fitted trace (red dashed line). Figure 4 shows the SNR, aspect angle and altitude along the trace shown by the dashed red line in Figure 3. The peak of the SNR (red line) coincides remarkably well with the exact perpendicularity (green line) of the Bragg wavevector with the geomagnetic field. The altitude data (black line) shows that the peak SNR occurred at $102 \mathrm{~km}$.

[14] Lag (red line) and the echo Doppler velocity (blue line) computed from the same lag (as discussed previously). The green line shows the power originally computed from the I and Q samples. Note that since the correlation time of UHF coherent scatter is on the order of $1 \mathrm{~ms}$ [Hall and Moorcroft, 1988], the echo power computed from the ACF lag at $90 \mu \mathrm{s}$ is very well representative of the actual power. For the transmitted pulse of $100 \mu \mathrm{s}$, the power from the ACF lag of $90 \mu$ has a time resolution of $10 \mu \mathrm{s}$, corresponding to an altitude resolution of $3 \mathrm{~km}$. Note that the angle between incident and scattered wave is about $90^{\circ}$, therefore, the range resolution is given by $c \Delta \tau$, not $c \Delta \tau / 2$ in the mono-static case.

\section{Discussion}

[15] Literature on plasma waves in the auroral electrojet has been reviewed in Haldoupis [1989], Sahr and Fejer [1996], and Moorcroft [2002], among others. Fejer et al. [1975] solved for the frequency and growth rate of the waves with wavevector $\mathbf{k}$ :

$$
\omega=\frac{\mathbf{k} \cdot\left(\mathbf{V}_{d e}-\mathbf{V}_{d i}\right)}{1+\psi}+\mathbf{k} \cdot \mathbf{V}_{d i}
$$

$\gamma=\frac{1}{1+\psi}\left[\frac{\psi}{\nu_{i}}\left\{\left(\omega-\mathbf{k} \cdot \mathbf{V}_{d i}\right)^{2}-k^{2} C_{s}^{2}\right\}+\frac{k_{\perp} \nu_{i}}{k^{2} L \Omega_{i}}\left(\omega-\mathbf{k} \cdot \mathbf{V}_{d i}\right)\right]-2 \alpha n_{\circ}$

where

$$
\psi=\frac{\nu_{e} \nu_{i}}{\Omega_{e} \Omega_{i}}\left(1+\frac{\Omega_{e}^{2}}{\nu_{e}^{2}} \frac{k_{\|}^{2}}{k_{\perp}^{2}}\right) .
$$

[16] In the above equations, $\mathbf{V}_{d e}$ and $\mathbf{V}_{d i}$ are the electron and ion drift velocities, $L$ is the transverse plasma density gradient scale length, $\alpha$ is the recombination coefficient, $\Omega$ and $\nu$ refer to gyro and collision frequencies (with neutrals) for the ions and electrons, and $\psi$ is the so-called anisotropy factor, which depends on the magnetic aspect angle. The $C_{S}$ term is the ion acoustic speed, which may be expressed as $C_{s}^{2}=K_{B}\left(\gamma_{e} T_{e}+\gamma_{i} T_{i}\right) / m_{i}$. The symbol $\gamma$ used here now refers to ratios of specific heats which vary slightly with altitude according to kinetic theory [Farley, 1963].

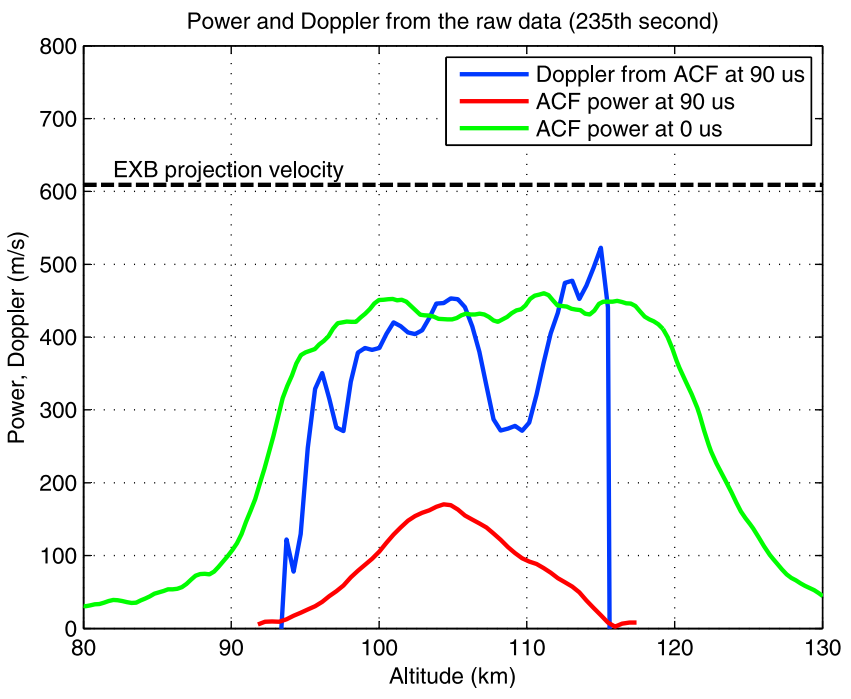

Figure 5. Raw echo intensity (green line), altitude-resolved intensity (red line) and Doppler velocity (blue line) as a function of altitude for the 235th second into the experiment (a vertical cut through the peak intensity in Figure 3). 


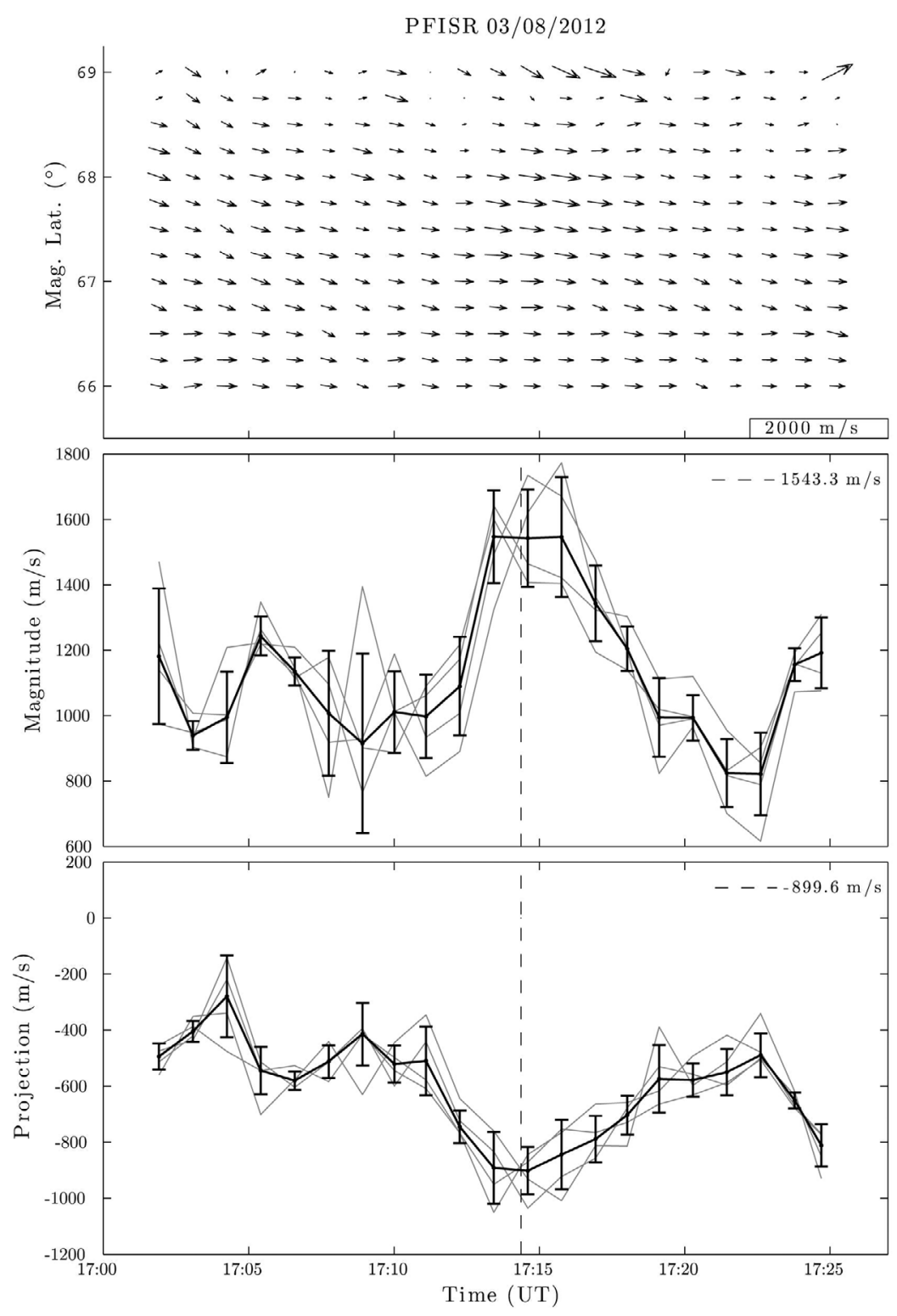

Figure 6. (top) Map of $F$ region ion velocities obtained from PFISR, (middle) time series of ion drifts at 5 different latitudes, and (bottom) the projections of the ion drifts on the PFISR-RAX bi-static Bragg wavevector.

[17] The above dispersion relation accounts for some of the properties of auroral $E$ region waves including (1) their excitation threshold, (2) their aspect sensitivity and (3) their Doppler spectrum. First, the echoes are only observed when the line-of-sight electron drift speed exceeds a threshold speed close to $C_{s}$. For this experiment, the ion drift velocities measured by the Poker Flat Incoherent Scatter Radar during the $300 \mathrm{~s}$ experiment had a magnitude greater than $1500 \mathrm{~m} / \mathrm{s}$, well exceeding the threshold $(\sim 500 \mathrm{~m} / \mathrm{s})$ for the FarleyBuneman instability. The electron densities were around $2 \times$ $10^{11} \mathrm{~m}^{-3}$. The Poker Flat magnetometer recorded a horizontal component of $\sim 550 \mathrm{nT}$, in line with large $E$ region electrical currents. Second, the radar echoes are highly aspect sensitive, with RMS aspect angles between $0.1^{\circ}-0.4^{\circ}$ [Kudeki and Farley, 1989]. Figure 4 clearly shows that the peak power coincides with the exact perpendicularity. Furthermore, the power fall of $10 \mathrm{~dB}$ occurs within $1-2^{\circ}$, in line with previous measurements at UHF [e.g., Hall and
Moorcroft, 1988]. Third, unlike the case of backscatter from the $F$ region, auroral $E$ region coherent echoes do not exhibit Doppler shifts that are proportional to the line-ofsight convection speed in the scattering volume (see recent reviews by Nielsen et al. [2002] and Uspensky et al. [2003, 2004]). According to $30 \mathrm{MHz}$ radar measurements reported in Bahcivan et al. [2005] and Hysell et al. [2008], the Doppler shift of the echoes are given by $C_{s} \cos \theta$ in the ion drift frame, where $\theta$ is the flow angle (between the radar Bragg wavevector and the main $\mathbf{E} \times \mathbf{B}$ flow direction) and the ion acoustic speed $C_{s}$ is estimated according to the empirical formula derived from STARE-EISCAT measurements by Nielsen and Schlegel [1985].

[18] The dashed horizontal line in Figure 5 shows the $\mathbf{E} \times$ B drift projection velocity $(\sim 600 \mathrm{~m} / \mathrm{s})$ on the Bragg wavevector. The measured Doppler velocities of $300-400 \mathrm{~m} / \mathrm{s}$ are lower than the dashed line, implying the saturation of the phase speeds. For this experiment, the $\mathbf{E} \times \mathbf{B}$ drift was 
measured to be $1543 \mathrm{~m} / \mathrm{s}$ and was mostly uniform in latitude (see Figure 6). According to Nielsen and Schlegel [1985], the formula for the ion acoustic speed at $105 \mathrm{~km}$ is $C_{S}=300+$ $0.00011\left(\mathbf{E} \times \mathbf{B} / B^{2}\right)$, which yields $562 \mathrm{~m} / \mathrm{s}$ for the measured $\mathbf{E} \times \mathbf{B}$ drift. Moreover, the flow angle $\theta$ was $54^{\circ}$ for the Bragg wavevector corresponding to the satellite position at the 235th second into the experiment. Combining these numbers, $C_{s} \cos \theta$ yields $328 \mathrm{~m} / \mathrm{s}$. Furthermore, we can estimate a collisional ion drift $V_{i}=E q_{i} / m_{i} \nu_{i}$ using an electric field $E=84 \mathrm{mV} / \mathrm{m}$ (corresponding to the $\mathbf{E} \times \mathbf{B}$ drift) and a collision frequency $\nu_{i}=1000 \mathrm{~s}^{-1}$, which yields $V_{i}=268 \mathrm{~m} / \mathrm{s}$. Adding the projection of $V_{i}$ on the Bragg wavevector $(156 \mathrm{~m} / \mathrm{s})$ to $C_{s} \cos \theta$ yields $484 \mathrm{~m} / \mathrm{s}$, which is in excellent agreement with the measured Doppler velocity of $\sim 450 \mathrm{~m} / \mathrm{s}$ for the altitude of $105 \mathrm{~km}$, as seen in Figure 5.

[19] Figure 5 also shows that the Doppler velocity is increasing with altitude. This can be due to either (1) the increase of the ion acoustic velocity due to larger electron heating at higher altitudes (up to a certain height $\sim 115 \mathrm{~km}$ ) [Schlegel and St.-Maurice, 1981; St.-Maurice et al., 1981] or (2) the variation in Hall and Pedersen ion velocities due to the altitude variation of the ion-neutral collision frequency. A gradual variation of the phase velocity with altitude was also observed in the ROSE rocket data [Dyrud et al., 2006]. Finally, we observe a dip in the Doppler velocity which is indicative of a wind shear, similar to what was seen during the first Joule experiment [Bahcivan et al., 2005].

[20] Meanwhile, the altitude distribution of the resolved power shown by the red line in Figure 5 is roughly consistent with the altitude variation of the total wave electric field RMS-fluctuation level measured by a $3.6 \mathrm{~m}$ boom on the downleg of the ROSE4 rocket [Dyrud et al., 2006]. The background electric field during this experiment was similar to the experiment discussed here $(\sim 70 \mathrm{mV} / \mathrm{m})$. Both profiles show wave activity starting $\sim 95 \mathrm{~km}$, while the rocket wave activity attenuates around $\sim 105 \mathrm{~km}$, below the altitude where the radar echoes terminate $(\sim 115 \mathrm{~km})$.

\section{Conclusion}

[21] Following a total of 18 ground-to-space radar experiments (end-to-end experiments each of which resulted in a 300 s range-time-intensity plot), the Radio Aurora Explorer CubeSat mission for the first time measured UHF auroral backscatter. The experiment coincided with the strong solar storm of March 8, 2012. The ground-to-space bi-static radar experiment that lasted $300 \mathrm{~s}$ was conducted in conjunction with the Poker Flat Incoherent Scatter Radar in the local morning $\sim 8 \mathrm{am}$ ) over Poker Flat, Alaska. The geomagnetic conditions were very active. During the experimental pass the Poker Flat magnetometer recorded horizontal magnetic deflection magnitudes of $\sim 550 \mathrm{nT}$. The conditions for the FAI generation in the $E$ region were optimal due to the strong ionospheric electric field $(\sim 75 \mathrm{mV} / \mathrm{m})$. An auto-correlation analysis mapped the distribution of $E$ region backscatter, for the first time, with $3 \mathrm{~km}$ resolution in altitude and sub-degree resolution in aspect angle. To our knowledge, these are the highest resolution (in altitude and aspect angle) UHF radar measurements made in the auroral region. Finally, the measured Doppler of the UHF scatter shows the saturation of the meter-scale plasma waves in line with previous findings and the observed Doppler velocity is in excellent agreement with the $C_{s} \cos \theta$ empirical formula. The measurements here extend the validity of this empirical relationship to the UHF frequencies. This work will be followed by another publication discussing the aspect sensitivity of meter-scale waves at finer angular resolution.

[22] Acknowledgments. RAX was developed under National Science Foundation grant ATM-0121483 to SRI International and the University of Michigan. PFISR operations and maintenance is supported by NSF cooperative agreement ATM-0608577 to SRI International.

[23] The Editor thanks Michael Kelley and Lars Dyrud for their assistance in evaluating this paper.

\section{References}

Bahcivan, H., and J. Cutler (2012), Radio Aurora Explorer: Mission science and radar system, Radio Sci., 47, RS2012, doi:10.1029/2011RS004817. Bahcivan, H., D. L. Hysell, M. F. Larsen, and R. F. Pfaff (2005), The $30 \mathrm{MHz}$ imaging radar observations of auroral irregularities during the JOULE campaign, J. Geophys. Res., 110, A05307, doi:10.1029/ 2004JA010975.

Bahcivan, H., M. C. Kelley, and J. W. Cutler (2009), Radar and rocket comparison of UHF radar scattering from auroral electrojet irregularities: Implications for a nanosatellite radar, J. Geophys. Res., 114, A06309, doi:10.1029/2009JA014132.

Dyrud, L., B. Krane, M. Oppenheim, H. L. Pecseli, K. Schlegel, J. Trulsen, and A. W. Wernik (2006), Low-frequency electrostatic waves in the ionospheric E-region: A comparison of rocket observations and numerical simulations, Ann. Geophys., 24, 2959-2979.

Farley, D. T., Jr. (1963), A plasma instability resulting in field-aligned irregularities in the ionosphere, J. Geophys. Res., 68, 6083-6097.

Fejer, B. G., D. T. Farley, B. B. Balsley, and R. F. Woodman (1975), Vertical structure of the VHF backscattering region in the equatorial electrojet and the gradient drift instability, J. Geophys. Res., 80, 1313-1324.

Haldoupis, C. (1989), A review on radio studies of auroral $E$-region ionospheric irregularities, Ann. Geophys., 7, 239-258.

Hall, G. E., and D. R. Moorcroft (1988), Doppler spectra of the UHF diffuse radio aurora, J. Geophys. Res., 93(A7), 7425-7440.

Hysell, D. L., G. Michhue, M. F. Larsen, R. Pfaff, M. Nicolls, C. Heinselman, and $\mathrm{H}$. Bahcivan (2008), Imaging radar observations of Farley Buneman waves during the JOULE II experiment, Ann. Geophys., 26, 1837-1850.

Kudeki, E., and D. T. Farley (1989), Aspect sensitivity of equatorial electrojet irregularities and theoretical implications, J. Geophys. Res., 94, 426-434.

Moorcroft, D. R. (2002), Outstanding issues in the theory of radar aurora: Evidence from the frequency dependence of spectral characteristics, J. Geophys. Res., 107(A10), 1301, doi:10.1029/2001JA009218.

Nielsen, E., and K. Schlegel (1985), Coherent radar Doppler measurements and their relationship to the ionospheric electron drift velocity, J. Geophys. Res., 90, 3498-3504.

Nielsen, E., C. F. del Pozo, and P. J. S. Williams (2002), VHF coherent radar signals from the $E$ region ionosphere and the relationship to electron drift velocity and ion acoustic velocity, J. Geophys. Res., 107(A1), 1012, doi:10.1029/2001JA900111.

Sahr, J. D., and B. G. Fejer (1996), Auroral electrojet plasma irregularity theory and experiment: A critical review of present understanding and future directions, J. Geophys. Res., 101, 26,893-26,909.

Schlegel, K., and J. P. St.-Maurice (1981), Anomalous heating of the polar $E$ region by unstable plasma waves: 1 . Observations, J. Geophys. Res., $86,1447-1452$.

St.-Maurice, J. P., K. Schlegel, and P. M. Banks (1981), Anomalous heating of the polar $E$ region by unstable plasma waves: 2 . Theory, $J$. Geophys. Res., 86, 1453-1462.

Uspensky, M., A. Koustov, P. Janhunen, R. Pellinen, D. Danskin, and S. Nozawa (2003), STARE velocities: The importance of off-orthogonality and ion motions, Ann. Geophys., 21, 729-743.

Uspensky, M., A. Koustov, P. Janhunen, E. Nielsen, K. Kauristie, O. Amm, R. Pellinen, H. Opgenoorth, and R. Pirjola (2004), STARE velocities: 2. Evening westward electron flow, Ann. Geophys., 22, 1077-1091. 